\title{
Analysis of a Self-learning System of English Flipped Classroom Based on Adaptive Algorithm
}

\author{
https://doi.org/10.3991/ijet.v13i08.9056 \\ Ying He \\ Sichuan Film and Television University, Chengdu, Sichuan, China \\ hying 709 @ $126 . \mathrm{com}$
}

\begin{abstract}
To solve the problem of how to apply information technology in English education field, to realize the integration of information technology and courses and also to truly improve the study efficiency, the advanced technologies were combined with some education measurement theories and applied in computer-aided test field. In addition, a computer-aided autonomous learning system with adaptive feature was developed, which was a self-adaptive learning system of junior English. The results showed that, under the guidance of the classic test theory and the project response theory, the system was designed and developed on the basis of the "people-oriented" principle. With the increasing number of students wanting to practice, the system dynamically rewrote the relevant learning record parameters, and conducted a real-time record of the true level of ability of each different student in different knowledge points. In a word, practicing according to the actual situation, the learning system can help achieve a truly personalized learning, and meanwhile enhances the efficiency of learning.
\end{abstract}

Keywords-adaptive learning system; self- learning; flipped classroom; teaching

\section{$1 \quad$ Introduction}

English is the universally used language and plays an important role in students' academic and career development. In the context of information age, the focus of English education is changing from educating to learning, and from educators to learners. Learners and learning fields have become the focuses of English education research. How to apply information technology to English education, to realize the integration of information technology and curriculum, and to truly improve the efficiency of English learning, are important aspects of the development of educational technology in the process of informatization.

The "flipped classroom" originating from the United States, which is also known as the "inverted classroom" or "flipped classroom", is a teaching mode different from the traditional classroom teaching of knowledge and homework completion teaching mode. Intel's global director of education, in the 2011 Annual Intel one-to-one digital learning annual meeting, described flipped classroom as the following. The flipped 
classroom is also known as inverted classroom. It refers to that the teacher gives students more freedom, lays the process of knowledge teaching out of the classroom, and enables students to choose their most suitable way to learn new knowledge. The processes of knowledge digestion is put in the classroom, so that there is more communication and view exchanges between teachers and students.

Flipped classroom is blended learning. It can promote comprehensive classroom reform, and it is the basic representation of effective classroom. If we combine English teaching with flipped classroom effectively, it will have a good influence on students' English-learning efficiency. However, the author has found that although the flipped classroom has triggered a series of domestic research upsurges, its practical effect has also been regarded by many scholars as "languid". One of the most important factors is that how to ensure the effect of first learning without the supervision of teachers before class is a difficult problem in the implementation. At present, usually a solution based on MOOC's flipped classroom is adopted. Students answer questions that teachers have pre-designed when completing watching or in the process of watching videos, so as to evaluate their master of knowledge points. But for this solution, the evaluation of individualization is not enough, which cannot accurately grasp the students' knowledge points and students' learning preference. Therefore, the author tries to introduce the adaptive learning system into the flipped classroom.

Adaptive learning system relies on student model, knowledge domain model and adaptive engine. It can record students' behavior data in their learning process, and then achieve the purpose of real-time evaluation and feedback through technologies such as data mining, learning analysis and etc. Finally, it gives feedback of students' learning results in visualization study report to teachers and students, so as to promote students' sustainable learning. In addition, it helps teachers to know students' blind spots of knowledge as well as learning preferences before class, and to provide corresponding technical support for targeted teaching in the class.

\section{State of the art}

Ruest, L. B. et al. [1] stated that the availability of electronic teaching content, including lectures, for self-learning was increasing rapidly and changing the way how course content was delivered. They also reported previously on the results of a study investigating whether the addition of active learning exercises improved student learning in a flipped classroom self-learning model. Wei, Q. et al. [2] developed a novel iterative adaptive dynamic programming ADP-based infinite horizon selflearning optimal control algorithm, called generalized policy iteration algorithm for nonaffine discrete-time (DT) nonlinear systems. Knoell, D. et al. [3] held the opinion that self-learning support systems were being successfully used to support sophisticated processes. He provided an example-driven view on the Bishop project for Big Data driven self-learning support for high-performance ontology population.

Z. Jinlei et al. [4] points out that flipped classroom is a classroom that swaps the arrangement of knowledge imparting and knowledge internalization. In the flipped classroom, teachers' and students' roles have been changed and the class time has a 
new plan. Information technology and activity learning construct an individuation and cooperative learning environment for learners to create new learning culture. C. F. Herreid et al. [5] listed the advantages of the "flipped classroom". Firstly, students move at their own pace. Secondly, doing "homework" in class gives teachers better insight into student difficulties and learning styles. Thirdly, teachers can more easily customize and update the curriculum and provide it to students. Fourthly, classroom time can be used more effectively and creatively. Fifthly, teachers using the method report seeing increased levels of student achievement, interest, and encouragement. Sixthly, learning theory supports the new approaches. Seventhly, the uses of technology is flexible and appropriate for " 21 st century learning". JD Tune et al. [6] pointed out that the flipped classroom model was a highly effective means to disseminate key physiological concepts to graduate students. L. Abeysekera et al. [7] constructed a theoretical argument that flipped approaches might improve student motivation and help manage cognitive load. They also concluded with a call for more specific types of research into the effectiveness of the flipped classroom approach. Hertz M. B. et al. [8] pointed out the essence of the learning mode. Learning is centered on the student, instead of the teacher. Learning allows students to show their mastery of content in the way they prefer.

Yousefi, R. et al. [9] proposed a novel real-time adaptive algorithm for accurate motion-tolerant extraction of heart rate (HR) and pulse oximeter oxygen saturation (SpO2) from wearable photoplethysmographic (PPG) biosensors. Xing, M. et al. [10] proposed an adaptive, best-action search algorithm to obtain a sub-optimal solution and the experiment results demonstrated the feasibility and effectiveness of the proposed adaptation algorithm for mobile video streaming applications, which outperformed the existing state-of-art adaptation algorithms. Qarib H. et al. [11] gave a novel adaptive control algorithm that is based on policy iteration and implemented it using an actor/critic structure with two adaptive approximate structures.

To sum up, self-learning, flipped classroom, and adaptive algorithm are introduced in this part among which flipped classroom is given great focus on its definition, advantages, related argument as well as its essence. However, there is relatively less research on adaptive algorithm, which needs more attention and further study. In view of this situation, this paper will conduct a theoretical study and explicate the adaptive algorithm from the design concept and structure of this system, which will greatly advance the study in this field theoretically and structurally without any doubt.

The details of the study are shown in the following parts.

\subsection{Classical test theory}

The classical test theory is also called the true fraction theory. It is the most general and basic theory of the test, which has a strong influence on the field of education and measurement, and plays an important role in guiding.

The classical true fraction theory puts forward the basic assumptions of three aspects, which are the logical premises of the classical measurement theory. The first assumption is that, within the scope of the problem discussed, the true fraction is invariable, that is, the individual has a constant characteristic, whose component is 
constant and the value is also a constant. The second assumption is that, the error is completely random. There are two meanings about the error is completely random . One is that the measurement error is the normal random variable with the average number (the expected value) as zero. The second meaning is that the measurement error is independent from the psychological trait of the subject, that is, the true score is not influenced. The third assumption is that, the observed fraction is the sum of the true fraction and the error fraction.

\subsection{Item response theory (IRT)}

The item response theory (IRT) is a new emerging psychological and educational test theory, which was developed on the basis of analyzing and overcoming the limitations of the classical test theory. Trait and item are the core concepts of item response theory. The relationship between the two is the main connotation of IRT. The item response theory is mainly embodied as the normal shoulder curve model and the logistic model.

The normal shoulder curve model is shown as formula (1).

$$
\mathrm{P}_{\mathrm{i}}(\theta)=\int_{-\infty}^{a_{i}\left(\theta-b_{i}\right)} \frac{1}{\sqrt{2 \pi}} e^{-\frac{z^{2}}{2}} d z
$$

The characteristic curve of the two-parameter normal shoulder curve model is shown in Figure 1.

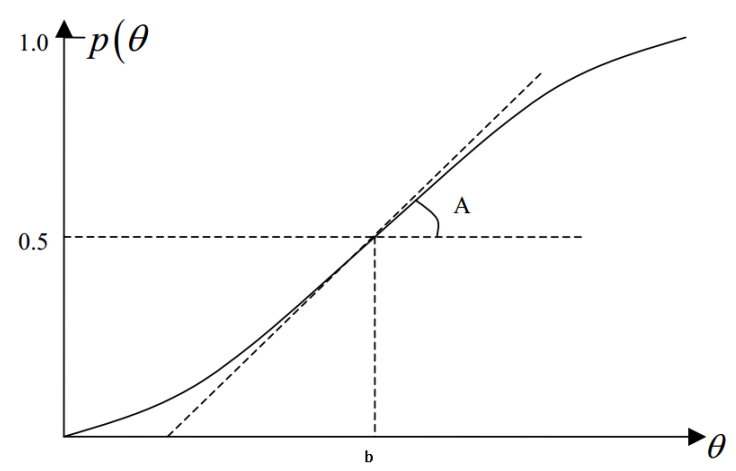

Fig. 1. The two parameters normal shoulder curve

The Logistic model is as shown in Figure 2. 


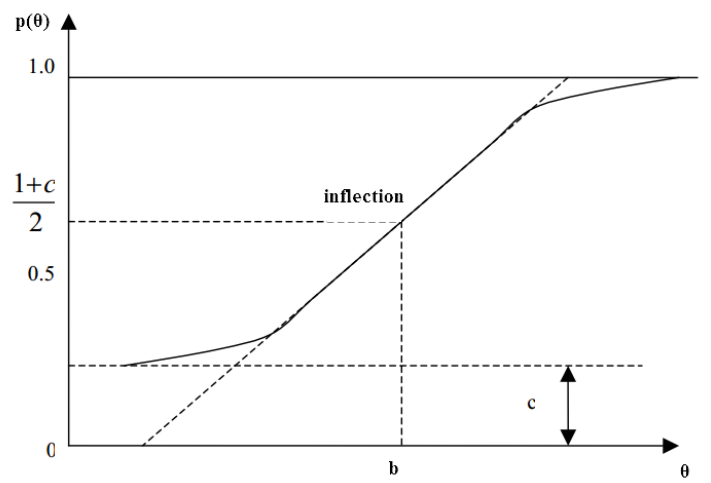

Fig. 2. The characteristic curve of the three parameters Logic item

The characteristic curve of the item describes the relationship between the score of the test and subjects' potential trait (ability) level. In the picture, each participant has different latent trait levels (abilities), expressed by $\theta$; and $\mathrm{Pi}(\theta)$ indicates the probability of correct answer to item $i$ (the $i$-th question) as $\theta$. The correct probability of a test project with a certain trait level is only related to the quality of the project (namely the question). Generally speaking, the trait level of a subject can be regarded as continuously changing. Therefore, it is a smooth curve that reflects the probability of the answer probability of subjects at all levels. The higher the trait level is, the greater the probability is. As a result, the curve should be a monotone increasing function curve. After studying, the relationship between the right answer probability and its equal level is nonlinear. When the level of trait $\theta$ is larger or smaller to a certain degree, the speed of the correct answer probability $p(\theta)$ becoming smaller or larger is significantly slower. The study shows that the shape of the curve is an S-shaped curve with its stronghold as the center of symmetry.

\section{Basic principle of computer adaptive test}

Computer adaptive test is a test developed on the basis of the item response theory. The essence of it is to find questions that are suitable for the student level from the question bank, and let the students answer them, so as to show their abilities or qualities.

The specific design process of the computer adaptive test is as follows.

The process of adaptive test is divided into two modules. The first module is exploring subjects' abilities, so as to set the initial value of the test. The general practice is to get the medium-difficult subjects randomly from the question bank. If students can answer the questions correctly, they will continue with more difficult ones. If students can't correctly answer the medium-difficult questions, they will be given easier ones. According to their answers, we can estimate their ability values. The second module is constantly correcting subjects' abilities. According to the initially estimated ability value, we continue to extract the most suitable-difficult subjects 
from the question bank to test the subjects, and adjust the students' ability constantly according to their answers, so as to make an accurate evaluation of their authentic ability. The block diagram is shown in Figure 3.

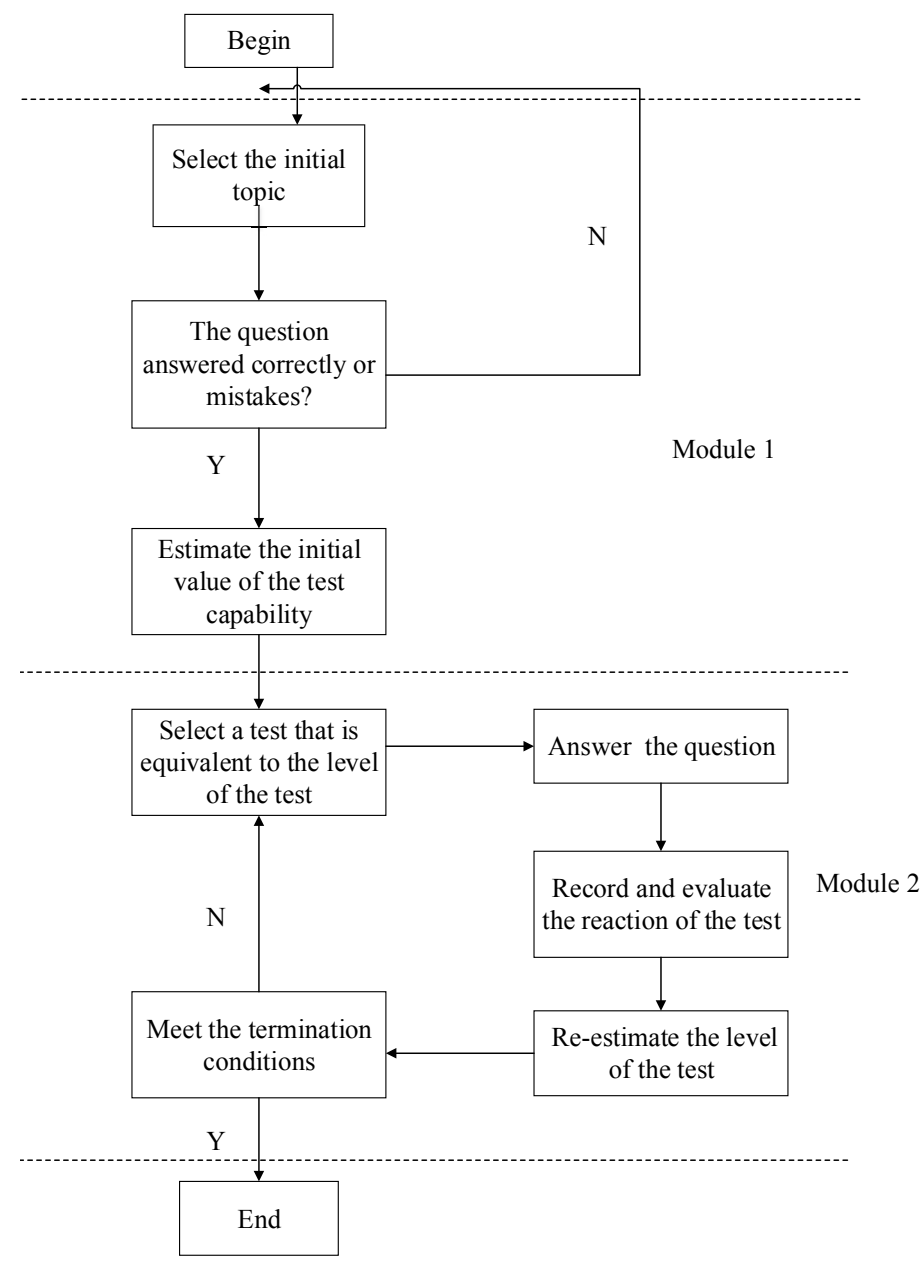

Fig. 3. Adaptive test flow chart

\section{Self-learning system design of English flipped classroom based on adaptive algorithm}

\subsection{System logic model}

The overall logic structure of the system is illustrated by the diagram. It is made up of four basic parts with independent logic: user layer, test layer, support layer and management layer. 
User layer: this layer is a browser interface that directly interacts with users. It is used to receive user input and display information returned from WEB server, which sets up two different identities of student and administrator.

Test layer: the layer embodies the concept of adaptive test, and its physical entity is a well prepared knowledge base and an adaptive test question bank.

Support layer: the support layer is a set of data stored in the database. This layer is mainly composed of three parts, i.e. adaptive test library, student feature library and knowledge base. The adaptive test question bank is a set of test questions and their attribute parameters which are corrected by measurement. The student feature library stores the ability of students at each point of knowledge. Knowledge base stores learning resources (that is, related knowledge points). The contents of each library are rewritten dynamically by the system according to a certain principle, or by the maintenance manager in accordance with the circumstances. The support part is the fundamental guarantee of achieving adaptive learning in the learner's adaptive learning system.

Management layer: the main function of this layer is to initialize, maintain and manage the data of the support layer, as well as maintain the whole teaching platform and the information release.

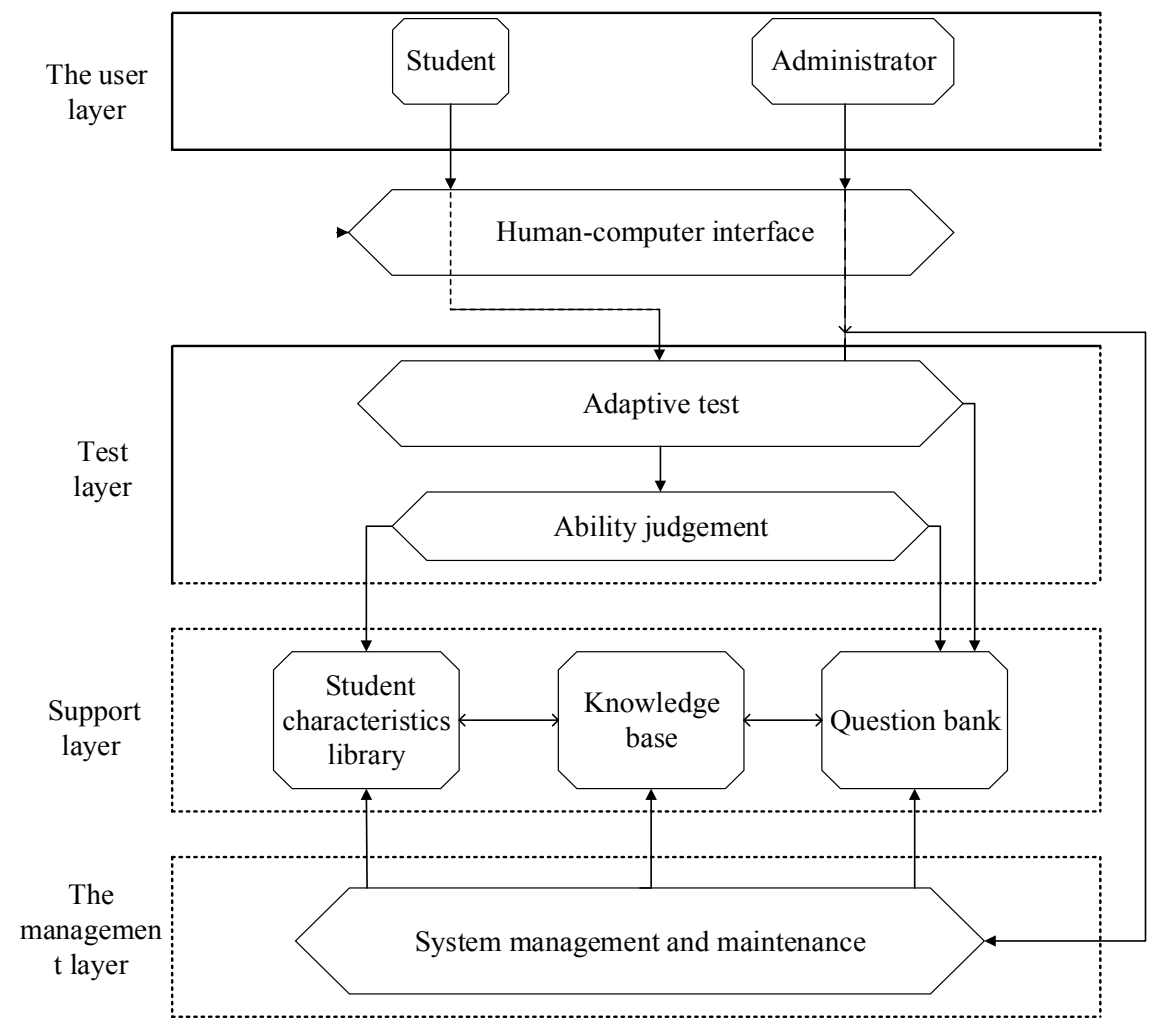

Fig. 4. System logical structure diagram 


\subsection{Function module design}

From the learner's perspective, new-user registration function is to fill in some necessary information, and the system assigns the unique symbol ID to each applicant. Log-in function: users with different identities use the user name to log in and enter different use pages according to different privileges. Information-modification function: ID is fixed and cannot be modified, but username, password, and email can be modified. Question-answering function: we can choose the way for questionanswering according to our own needs, and answer questions according to the unit and the knowledge point. Record-checking function: students can see and check the details of the subjects, and also see the details of the wrong subjects. By checking all of these records, they can be linked to relevant knowledge points. Error-modification function: they can redo errors according to the unit or according to the knowledge points. My library function: in the process of answering the questions, we can add the existing questions to "my question bank".

From the administrator's perspective, user-managing rights is to create new users, modify user data, delete users, give or modify user rights. Knowledge-points management: to add, delete, and modify the classification of knowledge points and modify other information of the knowledge points. Question bank management: to add, delete, and modify the subject. User's learning records checking.

Based on the analysis of the system requirements above, the design of the functional modules of the system is shown in Figure 5.

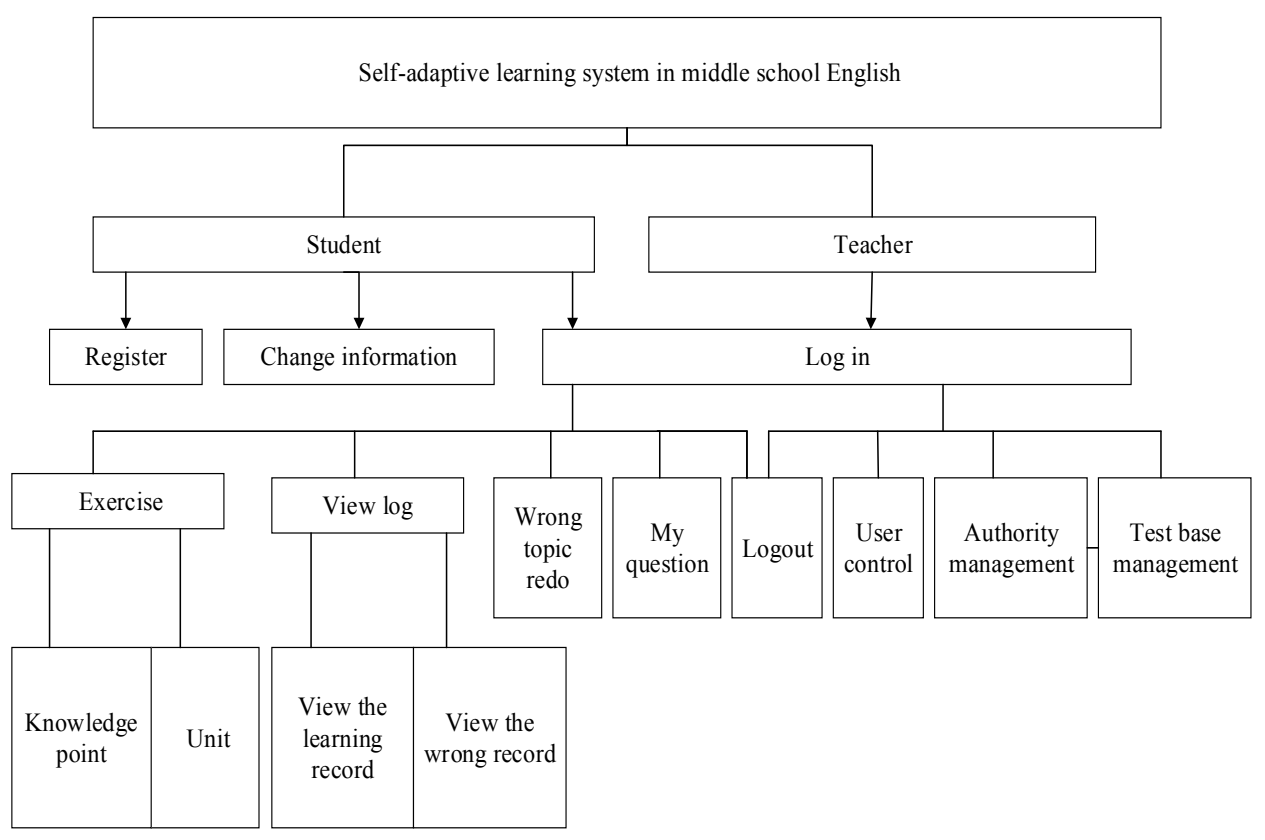

Fig. 5. Design diagram of system function modules 
Public module: User log-in and log-off. Both the student users and teacher users need to $\log$ in the system, and only in this way can they carry on various operations. At the same time, teachers and students can leave this system by cancellation.

Student module. New User Registration users who use the system must fill in some basic information for registration. Question Answering: the function of question answering is the key and difficult point of the system design, and it is also the embodiment of the adaptive test. Two different ways are designed for students to choose questions: do exercises according to knowledge points and do exercises according to the unit, which break the traditional question-making method with chapters as its main part. These two forms of question-answering both use the idea of self-adaptive test, and students can choose the way of question-answering according to their own needs. Record-checking: the record-checking function provides a platform for students to understand their learning situation at any time, and students can grasp the situation of their study in time. The record-checking has two sub-items available: checking learning record and viewing the error record. Students can check the details of all the subjects and the details of all the wrong subjects. And by checking these records, they can connect to the relevant knowledge points. Error-redoing: it provides two ways of redoing errors: according to the knowledge points and according to the unit. If a student chooses a knowledge point or a unit, the wrong subjects will be presented according to the wrong frequency from high to low in the selected range, so that users can be trained to aim at their weaknesses. My Question Bank: "my question bank" is equivalent to an electronic wrong title of students. In the question-making process, the difficult and wrong problems can be added to "my question bank" by students. They also can add the title, and manage the title that they added, and choose the recombinant test in "my question bank" for the test.

Administrator module. User Management is to realize the management of users, such as adding or deleting users. Authority Management: the authority management function is used to realize the management of the administrator of the user's rights, and the administrator gives the user the right authority according to the actual situation. Question Bank Management: the management function of the question bank is mainly to realize the function of adding, modifying and deleting the titles in the question bank. For this function, only the system administrator has the authority to operate.

Its functional structure is shown in Figure 6.

\subsection{Design of database}

Data table structure: according to the requirement analysis of the system function, the design of the function module and the design of the question bank as well as the attributes of each database table of the system are designed as shown in the Tables 1 to 11 . 


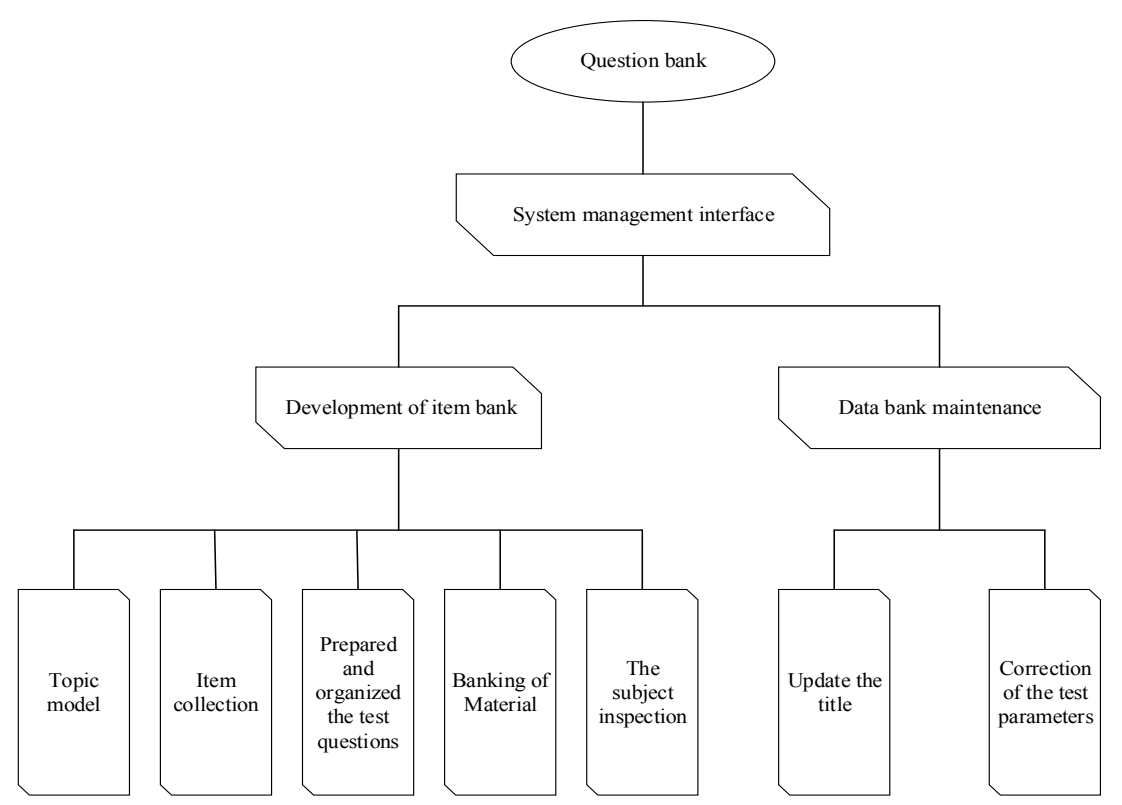

Fig. 6. The function structure diagram of the question bank subsystem

Table 1. Knowledge point table tbKP

\begin{tabular}{|l|c|c|c|}
\hline \multicolumn{1}{|c|}{ Attribute } & Data type & Uns size & NULLABLE \\
\hline KPID & char & 10 & $\mathrm{~N}$ \\
\hline Desc & ntext & 10 & $\mathrm{Y}$ \\
\hline ItemExa & ntext & 10 & $\mathrm{Y}$ \\
\hline ItemAna & ntext & 10 & $\mathrm{Y}$ \\
\hline GramAna & ntext & 10 & $\mathrm{Y}$ \\
\hline ForeKPID & char & 10 & $\mathrm{Y}$ \\
\hline UnitID & char & 10 & $\mathrm{Y}$ \\
\hline
\end{tabular}

Table 2. Unit table tbUnits

\begin{tabular}{|l|c|c|c|}
\hline \multicolumn{1}{|c|}{ Attribute } & Data type & Uns size & NULLABLE \\
\hline UnitID & char & 10 & N \\
\hline Term & char & 10 & Y \\
\hline Module & char & 10 & Y \\
\hline Unit & char & 10 & Y \\
\hline
\end{tabular}


Table 3. Test questions table tbItem

\begin{tabular}{|l|c|c|c|}
\hline \multicolumn{1}{|c|}{ Attribute } & Data type & Uns size & NULLABLE \\
\hline ItemID & char & 10 & $\mathrm{~N}$ \\
\hline ItemDesc & ntext & 16 & $\mathrm{~N}$ \\
\hline ItemA & ntext & 16 & $\mathrm{Y}$ \\
\hline ItemB & ntext & 16 & $\mathrm{Y}$ \\
\hline ItemC & ntext & 16 & $\mathrm{Y}$ \\
\hline ItemD & ntext & 16 & $\mathrm{Y}$ \\
\hline Answer & char & 10 & $\mathrm{Y}$ \\
\hline ItemAna & ntext & 16 & $\mathrm{Y}$ \\
\hline Diff & float & 8 & $\mathrm{Y}$ \\
\hline Div & float & 8 & $\mathrm{Y}$ \\
\hline KPID & char & 10 & $\mathrm{Y}$ \\
\hline UnitID & char & 10 & $\mathrm{Y}$ \\
\hline Switch & char & 10 & \\
\hline
\end{tabular}

Table 4. Student table tbStu

\begin{tabular}{|l|c|c|c|}
\hline \multicolumn{1}{|c|}{ Attribute } & Data type & Uns size & NULLABLE \\
\hline StuID & char & 10 & $\mathrm{~N}$ \\
\hline UserN & char & 10 & $\mathrm{Y}$ \\
\hline PassW & char & 10 & $\mathrm{Y}$ \\
\hline Name & char & 10 & $\mathrm{Y}$ \\
\hline
\end{tabular}

Table 5. Question answer table tbItemRec

\begin{tabular}{|l|c|c|c|}
\hline \multicolumn{1}{|c|}{ Attribute } & Data type & Uns size & NULLABLE \\
\hline ID & char & 10 & N \\
\hline StuID & char & 10 & Y \\
\hline ItemID & char & 10 & Y \\
\hline Choice & char & 10 & Y \\
\hline RorW & char & 10 & Y \\
\hline
\end{tabular}

Table 6. Error record table tbWItemRec

\begin{tabular}{|l|c|c|c|}
\hline \multicolumn{1}{|c|}{ Attribute } & Data type & Uns size & NULLABLE \\
\hline ID & char & 10 & $\mathrm{~N}$ \\
\hline StuID & char & 10 & $\mathrm{Y}$ \\
\hline ItemID & char & 10 & $\mathrm{Y}$ \\
\hline WTimes & int & 4 & $\mathrm{Y}$ \\
\hline RTimes & int & 4 & $\mathrm{Y}$ \\
\hline FreA & float & 8 & $\mathrm{Y}$ \\
\hline FreB & float & 8 & $\mathrm{Y}$ \\
\hline FreC & float & 8 & $\mathrm{Y}$ \\
\hline FreD & float & 8 & $\mathrm{Y}$ \\
\hline KPID & char & 10 & $\mathrm{Y}$ \\
\hline UnitID & char & 10 & $\mathrm{Y}$ \\
\hline
\end{tabular}


Table 7. Students' knowledge point table tbStuKP

\begin{tabular}{|l|c|c|c|}
\hline \multicolumn{1}{|c|}{ Attribute } & Data type & Uns size & NULLABLE \\
\hline StuID & char & 10 & N \\
\hline KPID & char & 10 & Y \\
\hline LevKP & char & 10 & Y \\
\hline
\end{tabular}

Table 8. Diagnostic test table tbPaper

\begin{tabular}{|l|c|c|c|}
\hline \multicolumn{1}{|c|}{ Attribute } & Data type & Uns size & NULLABLE \\
\hline ID & char & 10 & $\mathrm{~N}$ \\
\hline ItemNum & char & 10 & $\mathrm{Y}$ \\
\hline ItemID & char & 10 & $\mathrm{Y}$ \\
\hline
\end{tabular}

Table 9. Study record table tbStudyRec

\begin{tabular}{|l|c|c|c|}
\hline \multicolumn{1}{|c|}{ Attribute } & Data type & Uns size & NULLABLE \\
\hline StuID & char & 10 & Y \\
\hline Startime & Datetime & 8 & Y \\
\hline TimeNum & char & 10 & Y \\
\hline
\end{tabular}

Table 10. Teacher's table tbTeach

\begin{tabular}{|l|c|c|c|}
\hline \multicolumn{1}{|c|}{ Attribute } & Data type & Uns size & NULLABLE \\
\hline ID & char & 10 & Y \\
\hline UserN & char & 10 & Y \\
\hline PassW & char & 10 & Y \\
\hline
\end{tabular}

Table 11. Question bank table tbItemBase

\begin{tabular}{|l|c|c|c|}
\hline \multicolumn{1}{|c|}{ Attribute } & Data type & Uns size & NULLABLE \\
\hline ID & char & 10 & N \\
\hline StuID & char & 10 & Y \\
\hline ItemDesc & ntext & 16 & Y \\
\hline ItemA & char & 10 & Y \\
\hline ItemB & char & 10 & Y \\
\hline ItemC & char & 10 & Y \\
\hline ItemD & char & 10 & Y \\
\hline Answer & char & 10 & Y \\
\hline ItemAna & ntext & 16 & Y \\
\hline KPID & char & 10 & Y \\
\hline
\end{tabular}




\section{Conclusion}

This paper focuses on the design and development of adaptive self-learning system from both theoretical and practical aspects. On the basis of introduction and analysis of the current learning platform at home and abroad, the idea of item response theory is introduced into the system, which provides the direction for determining the test parameters and the ability level of the students. In addition, it established the overall framework of the "adaptive learning system" in its guidance, including logic theory, function module design, adaptive learning model and so on. It provides a feasible way for the transformation of the traditional network learning platform to the intelligent and adaptive system. Through this discussion, the following conclusions can be drawn.

Firstly, the implementation of an adaptive learning system means the following aspects: diagnosing students' ability level on knowledge points, changing students' feature library dynamically, and presenting the test questions that are most suitable for students' current ability level. Basically, it avoids the blindness which is easy to appear in the process of self-learning, and increases the pertinence and effectiveness of learning, as well as improves students' ability level in the process of practice.

Secondly, this system can promote students' acceptance of the concept of selflearning and embodies the main position of the students in the process of learning. To a certain extent, it will help the learners to improve their performance.

All in all, the society is a learning-oriented society and lifelong learning is inevitable, so how to learn will be paid more attention to and the study of self-adaptive learning will be of more practical significance.

\section{References}

[1] Ruest, L. B., Svoboda, K. K., \& Opperman, L. A. Student Survey Results on the Integration of Active Learning Exercises in a Dental Education Self-Learning Setting. The FASEB Journal, 2017, vol. 31(1 Supplement), pp. 576-13.

[2] Wei, Q., Liu, D., \& Yang, X. Infinite horizon self-learning optimal control of nonaffine discrete-time nonlinear systems. IEEE transactions on neural networks and learning systems, 2015, vol. 26(4), pp. 866-879. https://doi.org/10.1109/TNNLS.2015.2401334

[3] Knoell, D., Atzmueller, M., Rieder, C., \& Scherer, K. P. BISHOP-Big Data Driven SelfLearning Support for High-performance Ontology Population. In LWDA, 2016, pp. 157164.

[4] Z. Jinlei, Ying, W., \& Baohui, Z. Introducing a New Teaching Model: Flipped Classroom. Journal of Distance Education, 2012, vol. 4(8), pp. 46-51.

[5] C. F. Herreid, \& Schiller, N. A. Case studies and the flipped classroom. Journal of College Science Teaching, 2013, vol. 42(5), pp. 62-66.

[6] JD Tune, Sturek, M., \& Basile, D. P. Flipped classroom model improves graduate student performance in cardiovascular, respiratory, and renal physiology. Advances in physiology education, 2013, vol. 37(4), pp. 316-320. https://doi.org/10.1152/advan.00091.2013

[7] Abeysekera, L., \& Dawson, P. Motivation and cognitive load in the flipped classroom: definition, rationale and a call for research. Higher Education Research \& Development, 2015, vol. 34(1), pp. 1-14. https://doi.org/10.1080/07294360.2014.934336 
[8] Hertz, M. B. The flipped classroom: Pro and con. States News Service, July, 2012, pp. 1222.

[9] Yousefi, R., Nourani, M., Ostadabbas, S., \& Panahi, I. A motion-tolerant adaptive algorithm for wearable photoplethysmographic biosensors. IEEE journal of biomedical and health informatics, 2014, vol. 18(2), pp. 670-681. https://doi.org/10.1109/JBHI. 2013.2264358

[10] Xing, M., Xiang, S., \& Cai, L. A real-time adaptive algorithm for video streaming over multiple wireless access networks. IEEE Journal on Selected Areas in communications, 2014, vol. 32(4), pp. 795-805. https://doi.org/10.1109/JSAC.2014.140411

[11] Qarib, H., \& Adeli, H. A new adaptive algorithm for automated feature extraction in exponentially damped signals for health monitoring of smart structures. Smart Materials and Structures, 2015, vol. 24(12), pp. 125040 https://doi.org/10.1088/0964-1726/24/12/125040

\section{$7 \quad$ Author}

Ying He, Sichuan Film and Television University, Chengdu, Sichuan, China . Interest in research is foreign linguistics and Applied Linguistics (hying709@126.com).

Article submitted 17 April 2018. Resubmitted 20 May 2018. Final acceptance 23 June 2018. Final version published as submitted by the author. 